\title{
THE MEASUREMENT AND RECORDING OF GASTRODUODENAL BLOOD FLOW IN MAN BY MEANS OF A THERMAL GRADIENTOMETER ${ }^{1}$
}

\author{
By CHARLES H. RICHARDS, STEWART WOLF, ${ }^{2}$ AND HAROLD G. WOLFF \\ (From the Departments of Medicine and Psychiatry of the New York Hospital and the \\ Cornell University Medical College, New York)
}

(Received for publication March 16, 1942)

Measurement of blood flow in the intact human gut is desirable, not only because of its significance in physiological and pharmacological problems, but also because circulatory changes may be implicated in the mechanism of peptic ulceration. Studies on intestinal blood flow involving extensive surgical procedures with cannulation of arteries and veins have been carried out on animals (1 to 6), but the observations for the most part are contradictory, and, at best, deductions derived from them cannot be applied directly to human conditions. In other studies, inferences about the intestinal blood flow have been drawn from direct inspection of changes in calibre of the serosal vessels (7) and changes in color of the mucosa $(8,9)$.

\section{METHOD PREVIOUSLY DESCRIBED}

Recently, we reported a method of measuring and recording mucosal blood flow in man. This required of the subject only that he swallow a duodenal tube with a small balloon attached (10). On the surface of this balloon was mounted the measuring element consisting of a silver button with a heating coil and a thermocouple. The button was applied to the mucosa by inflating the balloon with air to a pressure of about 15 to $20 \mathrm{~mm}$. $\mathrm{Hg}$, and the reference couple was maintained at body temperature. When in place, the button was heated about $2^{\circ} \mathrm{C}$. above body temperature by connecting the heating coil to a source of constant current. Under these conditions, the actual temperature of the button varied according to the amount of heat lost by conduction to the blood flowing past it.

Two possible sources of error in the use of this apparatus were: (1) A change in area of the button actually in contact with the mucosa; and (2) movement of the button to a new position on the mucosa. In the first instance, the area of contact would affect the temperature

1 This investigation has been aided by a grant from the Josiah Macy, Jr. Foundation.

2 National Research Council Fellow in the Medical Sciences. of the button, and no method was available to distinguish between this effect and a change in blood flow. The second possibility of error was due to the fact that the temperature of the button was above that of the body and hence the tissue directly beneath it was warmer than the surrounding area. Therefore, any shift to an unheated area would cool the button until equilibrium was reestablished. This effect was impossible to distinguish from a change in contact area or a change in blood flow.

\section{PRESENT METHOD}

After trying several methods of circumventing these difficulties, the silver button was finally discarded in favor of the arrangement here described (Figure 1). A balloon, about $8 \mathrm{~cm}$. in length and $2.5 \mathrm{~cm}$. in its greatest diameter, has moulded into its wall 6 constantan-copper thermocouples equally spaced around its greatest circumference. The duodenal tube passes through the center of the balloon and on this tube is wound the heating coil with the reference thermocouples beneath it. The temperature of the heater is raised about $10^{\circ} \mathrm{C}$. above that of the body and heat is radiated to the whole surface of the balloon. Consequently, all the tissue in contact with it is warmed slightly above body temperature.

With this instrument, the errors previously encountered are minimized: (1) Since measurement is made at 6 points on the surface of the balloon and the couples are in series, the average temperature gradient between the heater and the balloon wall is recorded and the area of contact is less important; (2) since a much greater area of tissue is warmed than is actually used, considerable movement along the mucosa is possible without disturbing equilibrium at the points from which measurement is being made.

The apparatus was used with the subject in a fasting state to minimize the cooling effect which might be produced by the flow of intestinal contents past the balloon. To determine whether this factor could account for any of the observed results, a special balloon was constructed which was provided with a by-pass. Since experiments with this balloon gave identical results, it was assumed that this possible source of error was negligible.

It is important to note that this device measures the flow of blood past the balloon and not the amount of blood in the tissues. A decreased flow would be registered from a mucosa engorged with blood, if stasis and congestion were present. 


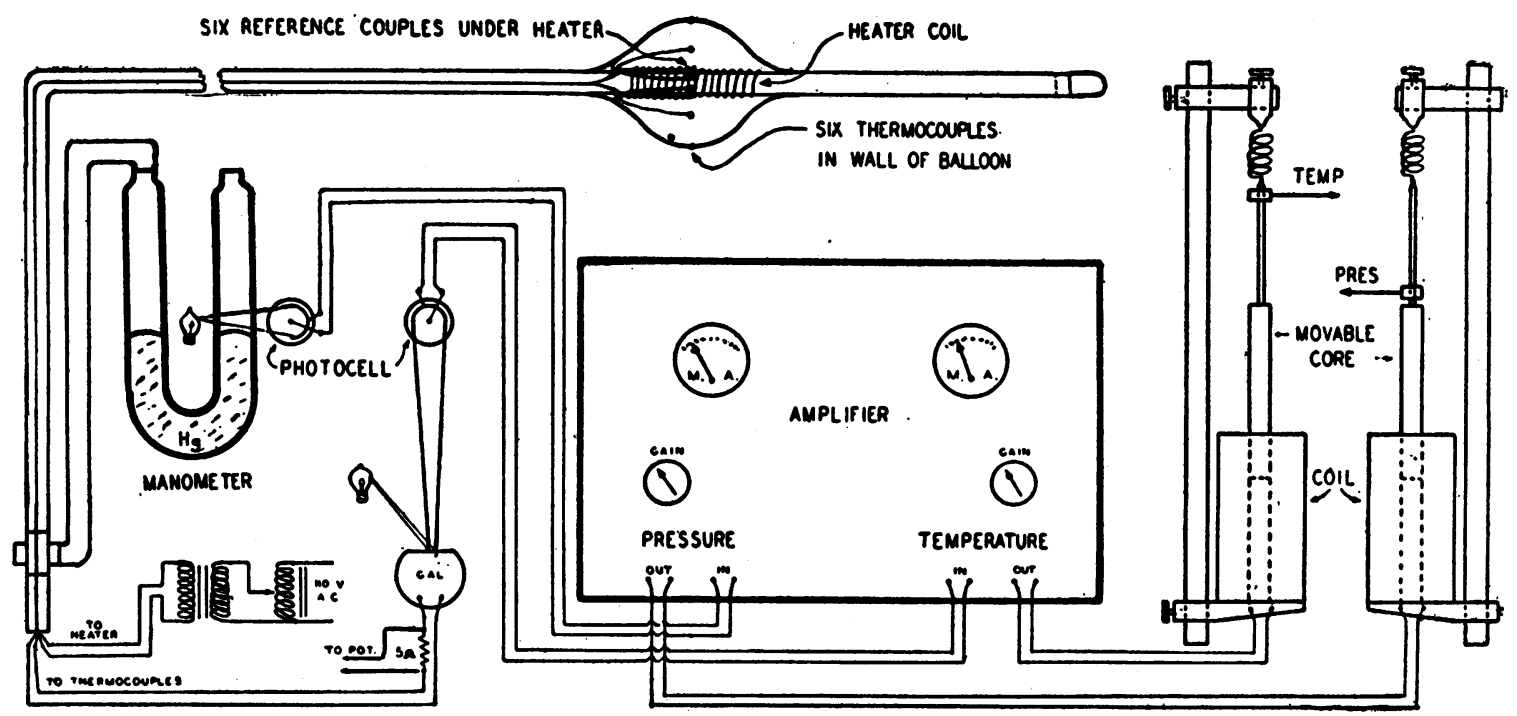

Fig. 1. New Apparatus Complete

\section{RECORDING}

Leads from the heater winding (which is about 100 ohms) are brought out through the tube and connected to a 10:1 stepdown transformer whose primary is operafed from the 110 volt line through a variable autotransformer. The thermocouple leads are connected to the galvanometer through an attenuator (omitted from Figure 1) and with a $5 \mathrm{ohm}$ resistor in series for the potentiometer (circuit shown in Figure 2). This is necessary because the output of the thermopile without this balancing device is too great for the galvanometer. The light from the galvanometer mirror is focussed on a phototube so that changes in temperature of the thermocouples vary the illumination of the phototube. The current through the tube is then amplified and fed into the solenoid whose movable core carries the writing point. The amplifier circuit is shown in Figure 3.

An identical amplifier and recording device is used to record contractions by connecting the tube from the balloon to a $\mathrm{Hg}$ manometer, one side of which is placed between a light source and a phototube so that variations in the $\mathrm{Hg}$ column vary the illumination of this phototube.

Thus there is obtained a continuous record of temperature changes (corresponding to changes in blood flow) and of pressure changes (i.e., contractions of the gut).

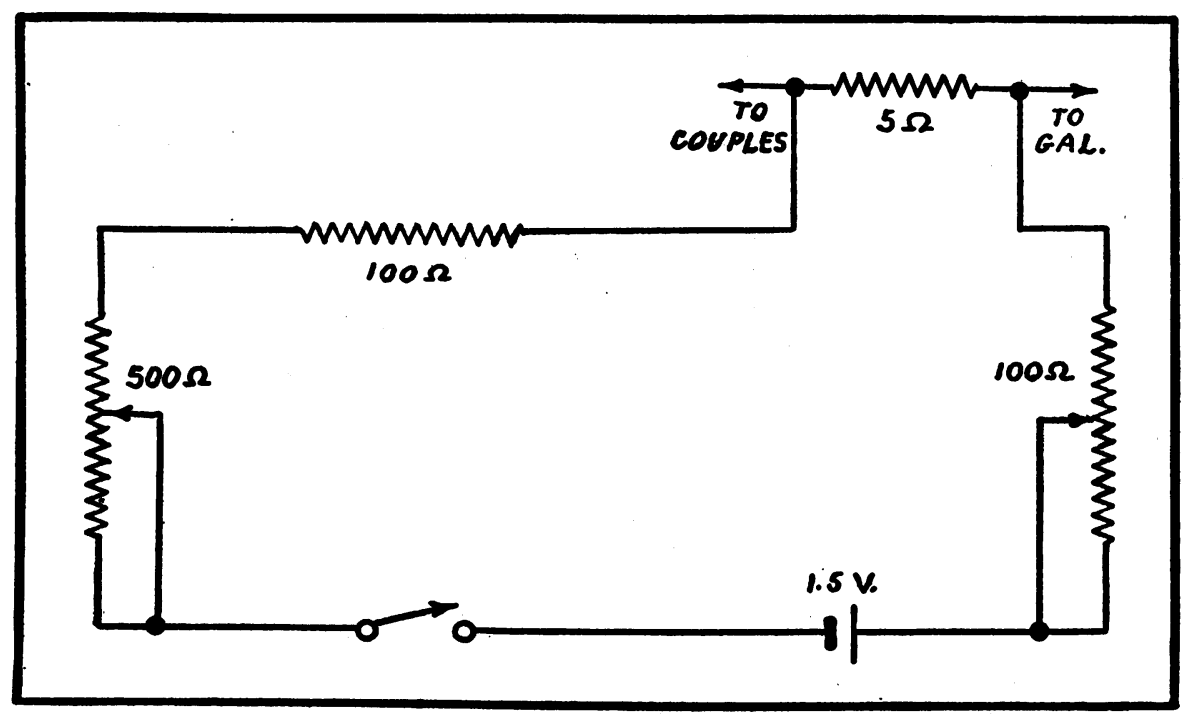

Fig. 2. Detail of Potentiometer Circuit 


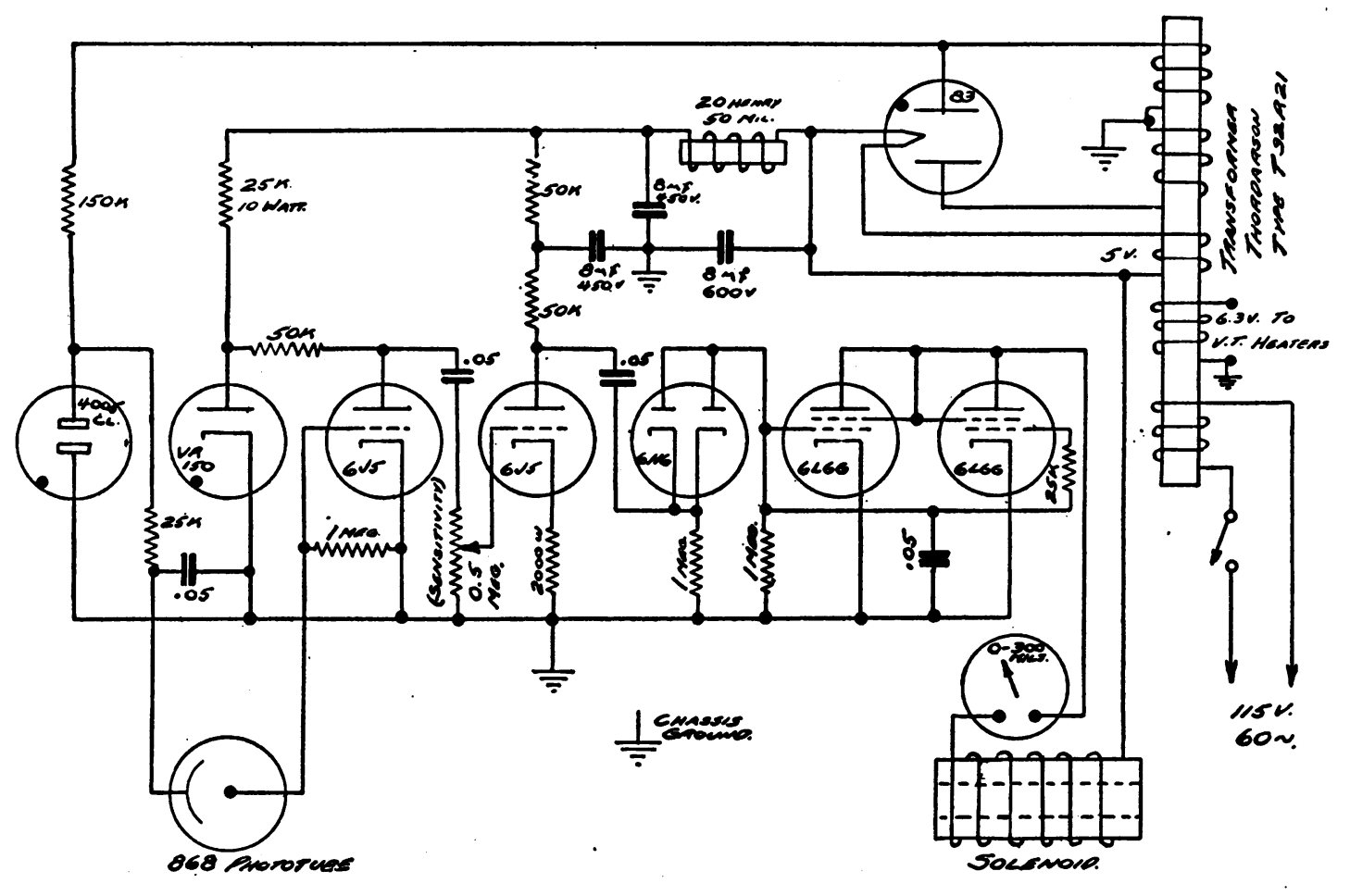

Fig. 3. Detail of Amplifier Circuit (designed by Wm. A. Geohegan, M.D., Dept. of Anatomy, Cornell University Medical College)

Illumination of the photocell applies negative half-wave 60 cycle voltage to the grid of the first $6 \mathrm{~J} 5$. After amplification, this is rectified and applied as a negative bias on the grids of the two $6 \mathrm{~L} 6 \mathrm{G}$ 's, decreasing the current through the recording solenoid. Records published here show a rather large variation of recorder position with line voltage, manifested particularly by large spikes produced by line voltage surges. This was due largely to the fact that the phototube is operated on a steep portion of its characteristic, and the difficulty has been overcome by regulating the applied phototube voltage as shown above, with the $4005 \mathrm{CL}$ neon lamp and its associated filter.

\section{OBSERVATIONS ON THE STOMACH}

1. Correlation of recorded blood flow with direct observation of color changes. With the balloon in place in the stomach observations were made on a subject with a large gastric fistula, whose gastric mucosa was readily accessible to view (9). While the blood flow was recorded, simultaneous observations of color changes in the mucosa were made. These changes were compared with a color scale ranging from 20 to 100 , the higher reading indicating increased redness (9). As shown in Figure 4, a spontaneous increase in recorded blood flow was associated with an obvious reddening of the mucosa and decreased flow with paling.

2. Effect of motility on blood flow. With each contraction of the stomach, there was a transitory acceleration of recorded blood flow and a coincident blushing of the gastric mucosa. Strong sustained contractions or cramps of the stomach were found to be associated with an initial increase of blood flow, followed by prolonged decrease. This decrease was accompanied by cyanosis and was therefore probably due to stasis and congestion.

3. Influence of histamine on blood flow (Figure 5). The intramuscular injection of $0.5 \mathrm{mgm}$. of histamine phosphate was followed within 15 minutes by a significant rise in blood flow which continued to increase up to 45 minutes after injection. With each gastric contraction, there was a further transitory wave-like acceleration of blood flow. One hour after injection the blood flow began to decrease and within 2 hours it had returned to its original base line. These changes 


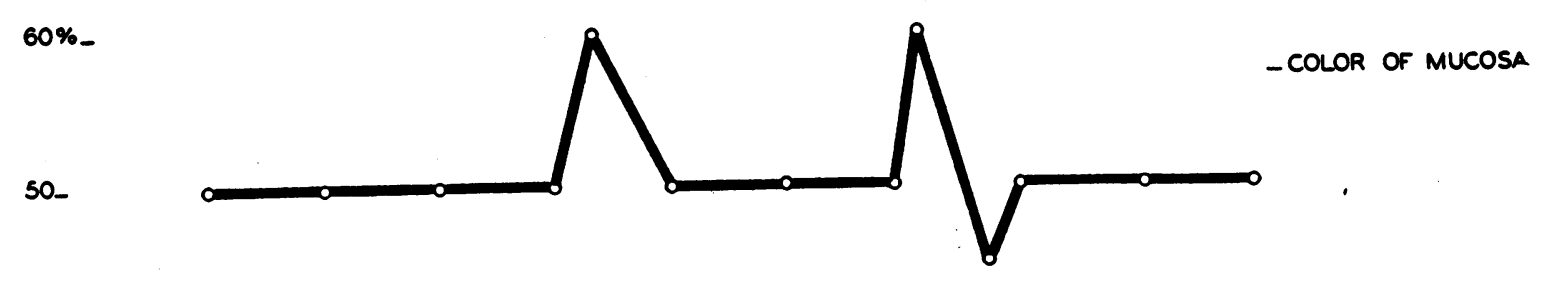

40
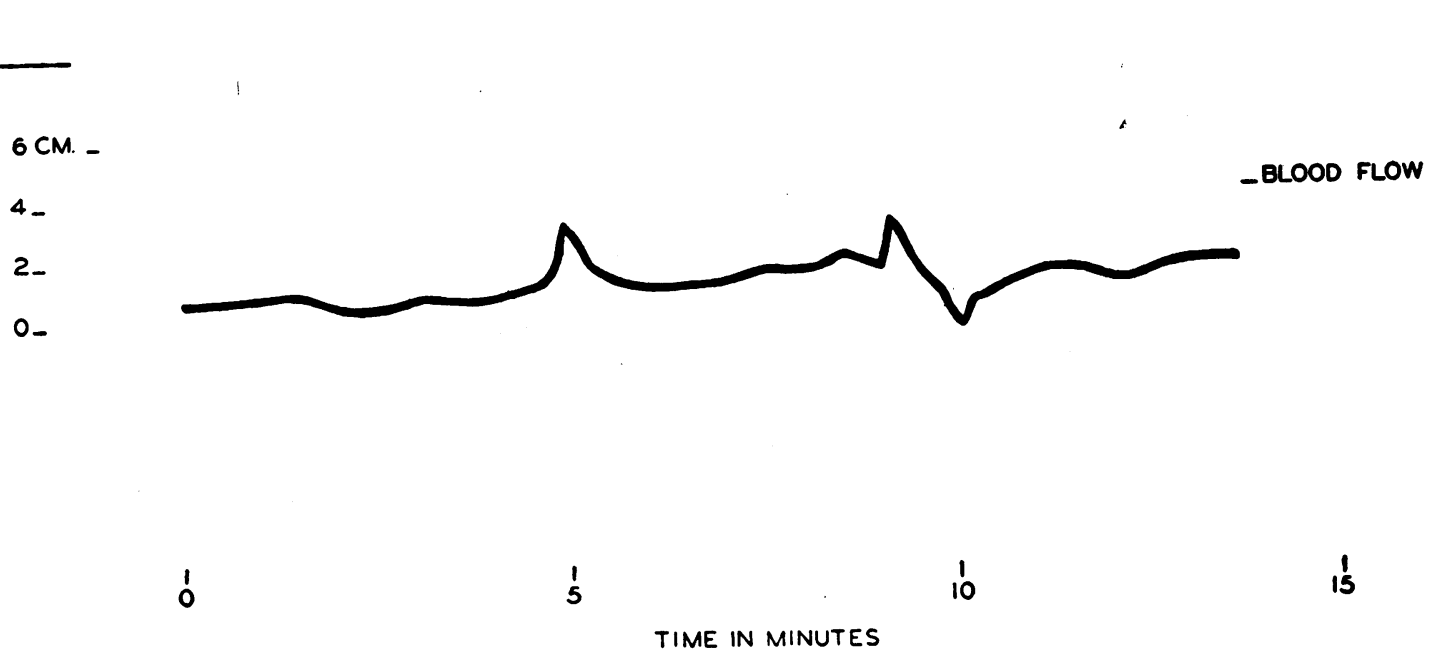

Fig. 4. Spontaneous Changes in Recorded Blood Flow in the Stomach Correlated with Changes in the Color of the Mucous Membrane Noted on Direct Inspection

The scale on the ordinate shows in centimeters the actual excursion of the recording needle from the base line with increase in blood flow.

in recorded blood flow following histamine paralleled the color changes of the gastric mucosa as ascertained by direct observation.

4. Effect of amyl nitrite and nitroglycerin on blood flow. Amyl nitrite inhalation $(1 \mathrm{cc}$.) and $0.6 \mathrm{mgm}$. of nitroglycerin placed under the tongue were followed by a variety of circulatory changes. Usually within 1 to 2 minutes after administration of these agents the gastric mucosa had become more red and engorged. At such times a simultaneous increase in blood flow occurred. At other times, especially with larger amounts of the nitrites and a fall in blood pressure, the mucosa became slightly cyanotic and the recorded blood flow either remained unchanged or was diminished.

\section{OBSERVATIONS OF THE DUODENUM}

1. Effect of motility on blood flow. As in the stomach, each short contraction of the duodenum was accompanied by a transitory acceleration of recorded blood flow. This effect is illustrated in Figure 6. During phases of frequent contractions, the base line is significantly higher than during quiescent phases.

2. Response to appetizing stimuli. The sight and smell of food in a hungry patient produced the effect on blood flow and motility which is shown in Figure 7. With a steady base line in both tracings, food was presented at the arrow. Within less than a half a minute strong contractions started and within one and a half minutes the blood flow began to increase. The latter effect lasted about 6 minutes, although the motility was altered for a longer period. Food which was not appetizing, on the other hand, evoked no such effects. Indeed, when actual distaste was encountered, a decrease in blood flow occurred. Figure 8 shows a sharp increase in blood flow and motility which occurred following a mere discussion of appetizing foods.

3. Changes associated with anxiety, tension and resentment. Feelings of anxiety, tension and re- 
sentment were evoked in one subject during an interview which focussed upon experiences with a business partner, who had in the subject's opinion betrayed and deceived him. A detailed per- sonality study of this patient is presented elsewhere (11). In Figure 9, an increase in blood flow is shown to be associated with this distressing emotional state. This graph was made by plot-

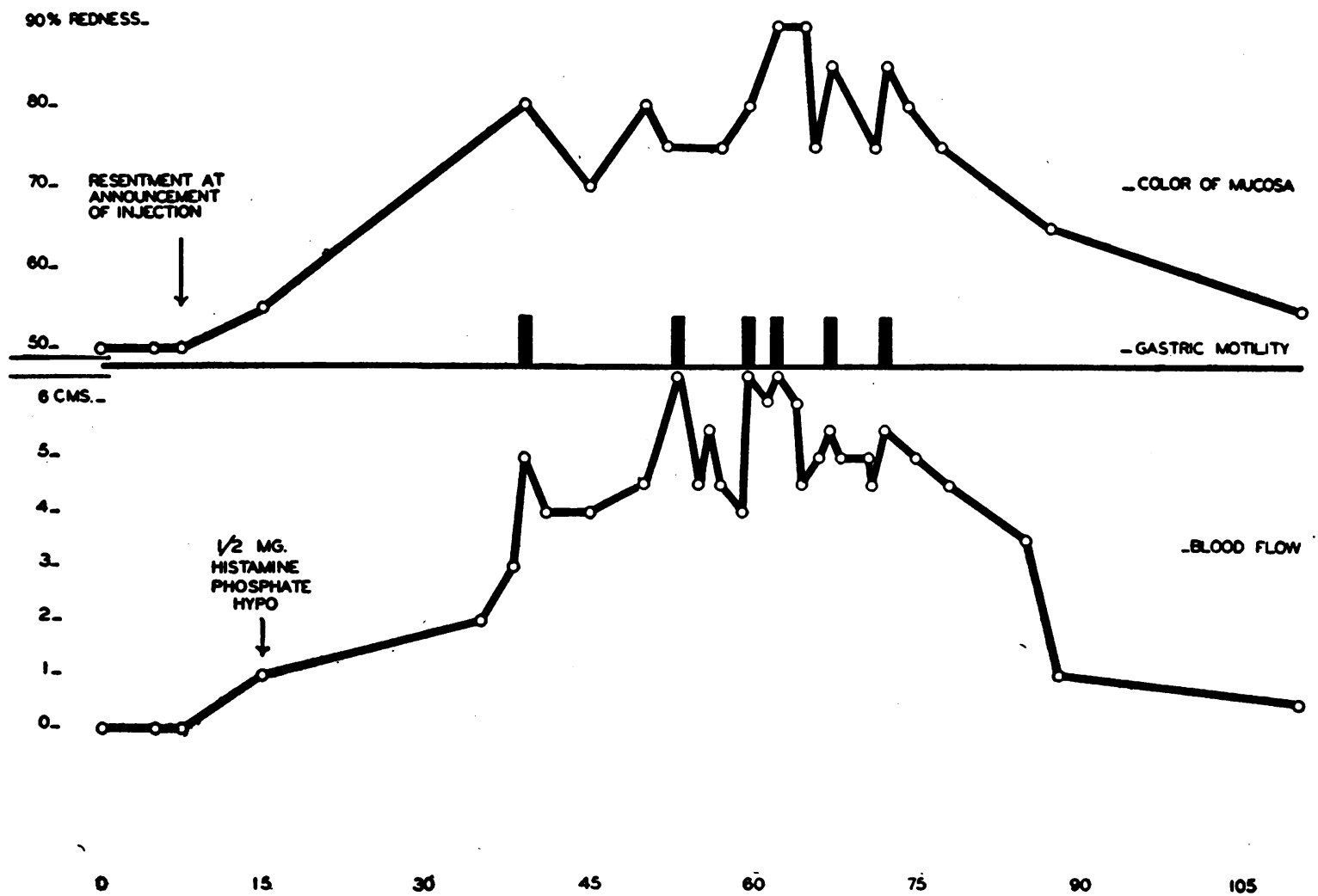

Fig. 5. Correlation of Color Changes and Changes in Recorded Blood Flow in the Gastric Mucosa After Histamine

Note transitory blushing and increased blood flow accompanying each major contraction. The contractions are indicated diagrammatically as solid columns. The record of blood flow is represented diagrammatically. The scale on the ordinate shows in centimeters the actual excursion of the recording needle from the base line with increase in blood flow.

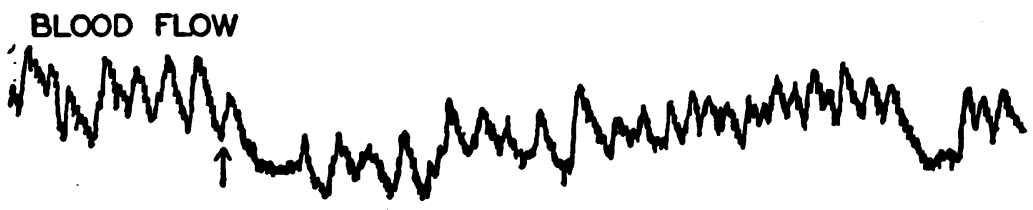

DUOD. CONTRACTIONS

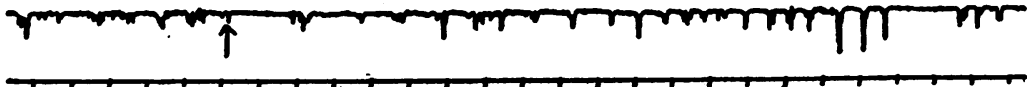

TIME IN MINUTES

Fig. 6. Correlation of Blood Flow with Contractions of the Wall of THe DuOdenum

The tracings of blood flow and motility are synchronous. 


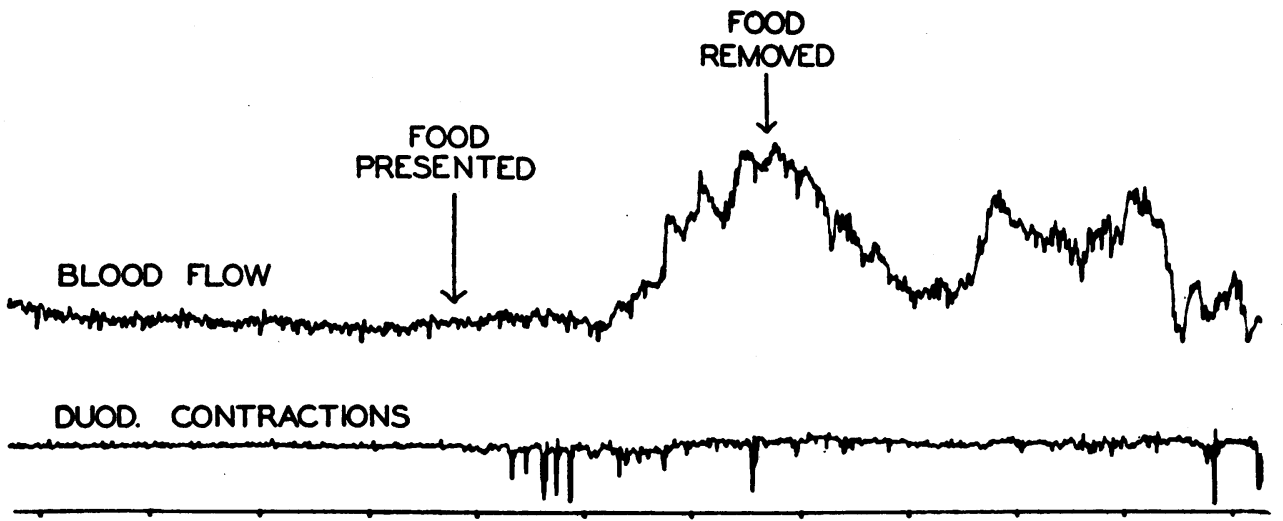

TIME IN MINUTES

Fig. 7. Changes in Blood Flow and Motility Associated with the Sight and Smell of Appetizing Food
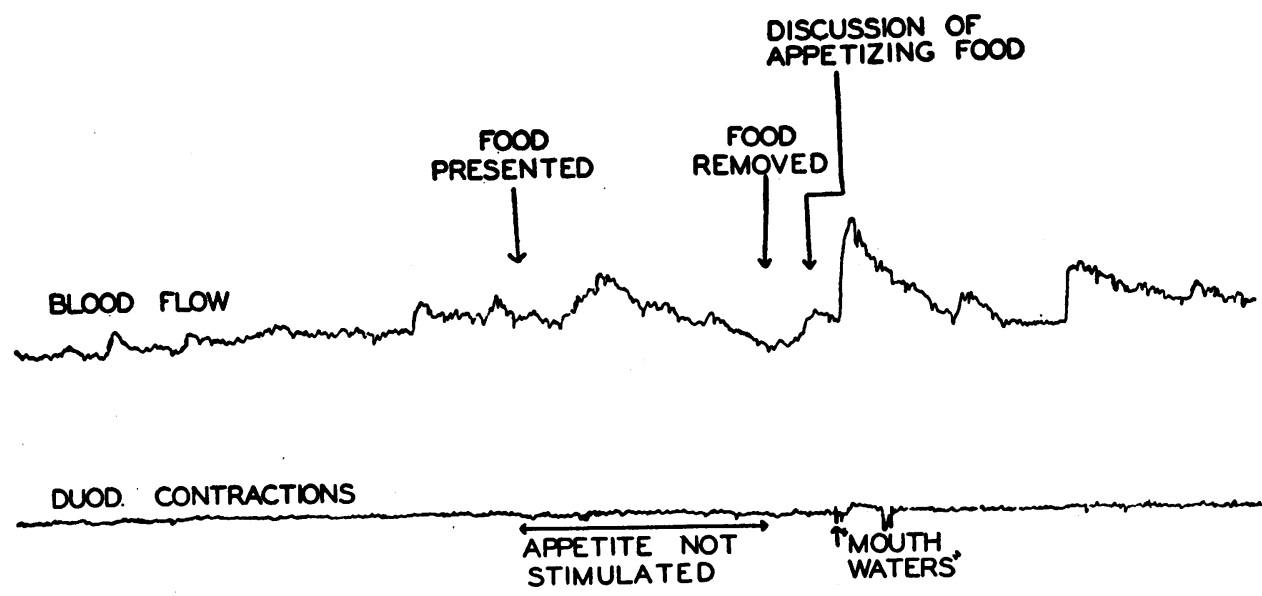

TIME IN MINUTES

Fig. 8. Changes in Blood Flow and Motility Associated with the Discussion of Appetizing Food

Note the absence of changes with the sight and smell of unappetizing food.

ting readings obtained directly from the galvanometer and manometer at 5 second intervals.

\section{DISCUSSION}

Changes in blood flow in the gastric and duodenal mucosae are here shown to occur under particular circumstances.

The transient increase in blood flow accompanying contractions of the stomach or duodenum is probably due to the mechanical effect of squeezing the blood out of the muscularis into the mucosa. If the contractions occur frequently enough, they may cause a sustained increase in flow. However, this factor alone cannot account for the large changes in flow shown in Figures 5, 7, 8, 9. It is probable for example that the increase with histamine is due to increased metabolic activity associated with hypersecretion, and the effect of the 


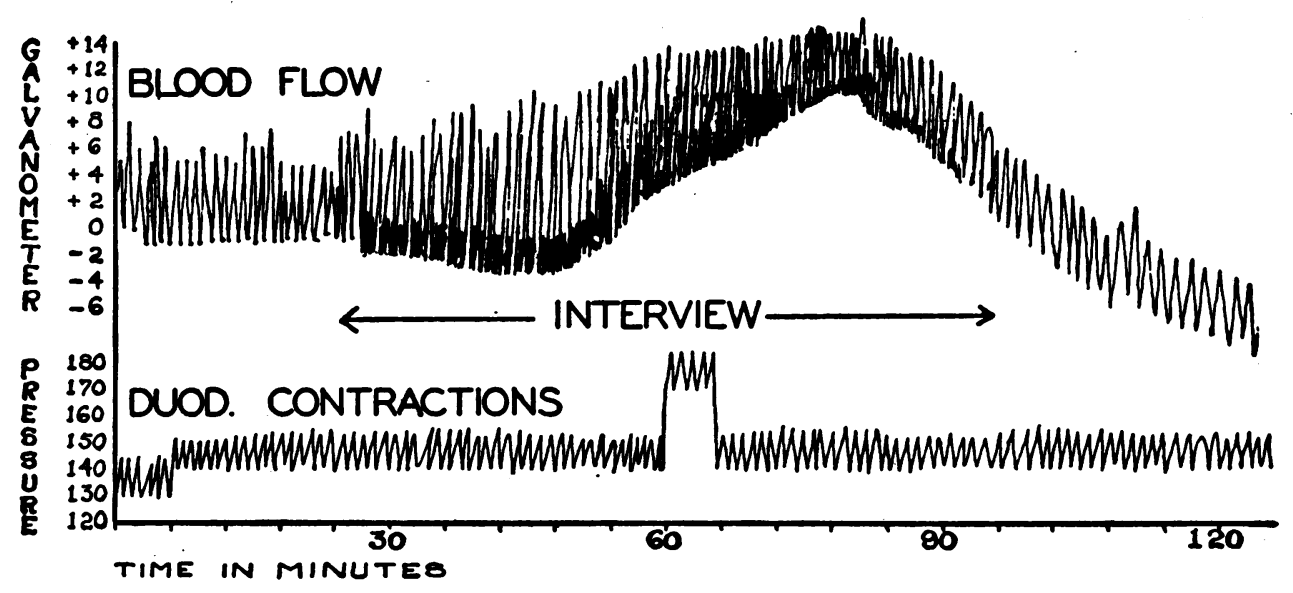

Fig. 9. Increase in Duodenal Blood Flow Accompanying Anxiety, Tension AND ResentMent

The pressure is calibrated in $\mathrm{mm}$. of water.

contractions is seen to be merely superimposed. Results of these studies on blood flow and motility will be correlated with secretory activity in another publication (9).

Anxiety, resentment and tension were seen to be associated with an increase in blood flow of the gastroduodenal mucosa. In the same subject, however, other emotional states such as fear, dejection and depression have been shown to be accompanied by a pale gastric mucosa and a decrease in secretion and motility (9).

The inference may be drawn that the blood flow of the gastroduodenal mucosa is determined by the interplay of three factors: (1) gastroduodenal motor activity, (2) the calibre of the blood vessels in the mucosa, and (3) the systemic arterial blood pressure.

\section{SUMMARY}

1. There has been described an improved instrument for measuring blood flow in the intact gastrointestinal tract of man, which requires of the subject merely that he swallow a small balloon attached to a stomach tube. Interpretation of the findings has been simplified and given added significance by correlation with direct observation of the color changes of the gastric mucosa in a patient with a large gastric fistula.

2. Contractions of the wall of the stomach and duodenum were accompanied by a transitory acceleration of blood flow.
3. Histamine induced a prolonged acceleration of blood flow in the gastric mucosa.

4. The contemplation, or even the mere discussion, of appetizing food was accompanied by an accelerated blood flow.

5. Anxiety, tension, and resentment were associated with accelerated blood flow.

\section{BIBLIOGRAPHY}

1. Rein, H., Vasomotorische Regulationen. Ergebn. d. Physiol., 1931, 32, 28.

2. Anrep, G. V., Cerqua, S., and Samaan, A., The effect of muscular contraction on the blood flow in the skeletal muscle, in the diaphragm and in the small intestine. Proc. Roy. Soc., London, s. B., 1934, 114, 245.

3. Lawson, H., and Chumley, J., Effect of distension on blood flow through the intestine. Am. J. Physiol., 1940, 131, 368.

4. Goetz, R. H., Control of blood flow through the intestine as studied by the effect of adrenalin. Quart. J. Exper. Physiol., 1939, 29, 239.

5. Lim, R. K. S., Necheles, H., and Ni, T. G., The vasomotor reactions of the (vivi-perfused) stomach. Chinese J. Physiol., 1927, 1, 381.

6. Cutting, W. C., Dodds, E. C., Noble, R. L., and Williams, P. C., Pituitary control of alimentary blood flow and secretion. Proc. Roy. Soc., London, s. B., 1937, 123, 27.

7. Kuntz, A., and Haselwood, L. A., Cutaneo-visceral vasomotor reflexes in the cat. Proc. Soc. Exper. Biol. and Med., 1940, 43, 517. 
8. Drury, A. N., Florey, H., and Florey, M. E., The vascular reactions of the colonic mucosa of dog to fright. J. Physiol., 1929, 68, 173.

9. Wolf, S., and Wolff, H. G., A Man and His Stomach. (To be published.)

10. Richards, C. H., Wolf, S., and Wolff, H. G., Studies on blood flow in the gastrointestinal tract in man. J. Clin. Invest., 1941, 20, 440.

11. Wolf, S., and Wolff, H. G., Intermittent fever of unknown origin: Study of recurrent high fever with benign outcome in a patient with migraine, and notes on "neurogenic fever." Arch. Int. Med., 1942. (In press.) 